\title{
Germany names candidate site for ITER fusion reactor
}

Munich. The university town of Greifswald in eastern Germany seems increasingly likely to be chosen by Germany as its proposed site for the next generation fusion reactor, the International Thermonuclear Experimental Reactor (ITER).

Last week, the Max Planck Society agreed to establish a new out-station of the Max Planck Institute for Plasma Physics (IPP) in Greifswald, which is in the state of Mecklenburg-Vorpommern (the native region of Germany's research minister, Paul Krüger), and situated on the north coast of the country.

Garching's second generation stellarator, Wendelstein 7-X, will be built there, rather than as previously planned at Garching, near Munich in the south of the country, where the IPP itself is based.

The German government's goal is to build up a service infrastructure and research environment around the new machine able to compete with other countries for the European bid for ITER, a decision due to be taken within the next couple of years.

At the same time, a department of theoretical plasma physics will be established at the University of Greifswald, with which project leaders at the IPP outstation will have joint appointments. Three new lectureships will also be created.

Wendelstein 7-X will cost DM500 million (US\$312 million) to build, half of which will be paid by the German government and 45 per cent through the European Union's fourth Framework programme. The rest will come from the state government of Mecklenburg-Vorpommern. The new machine will build on the work of its predecessor, currently operating in Garching, in determining optimal conditions for plasma burning.

Research teams at Garching have already indicated that they are prepared to move $800 \mathrm{~km}$ to Greifswald, accepting the pressure on the government to site important projects in the economically disadvantaged east of the country.

But the move is being made with resignation rather than enthusiasm. "We would have preferred Wendelstein 7-X built in Garching, where scientific communications would have been better and where much of the infrastructure is already in place," says a spokesman for the IPP. "Everything will have to be built from scratch at Greifswald," he adds. Indeed, Mecklenburg-Vorpommern will have to provide an extra DM120 million to establish the necessary infrastructure before building of the reactor can commence.

The decision to locate Wendelstein 7-X at Greifswald is part of the post-reunification programme to build up the dilapidated research base of east Germany. Since becoming research minister in May last year Krüger has clearly indicated his intention of backing a German bid to host ITER at Greifswald.

One implication is that a rival bid from the Karlsruhe Nuclear Research Centre (KfK), which has already been approved by the local state government of BadenWürttemberg, is almost certain to be out of the running. This will suit the many scientists at Karlsruhe, who were worried about

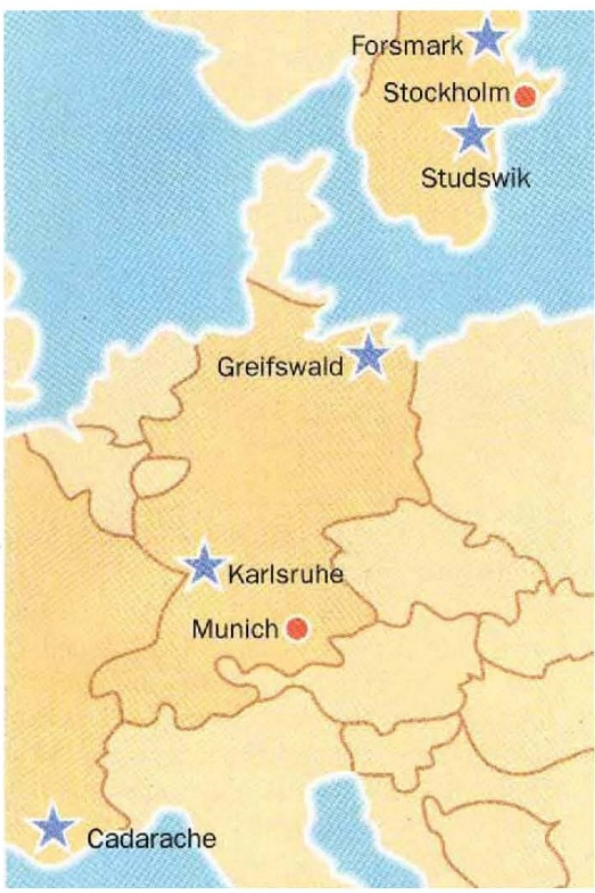

ITER: Europe faces five potential sites.

losing funding for their own projects to ITER.

To increase its chance of beating bids expected from Japan, the United States and possibly Russia, Europe will, through the European Atomic Community (Euratom), propose a single site for ITER. Other candidates in Europe currently include either Studsvik or Forsmark in Sweden and Cadarache in southern France.

A final decision on the location of ITER will probably take place in about two years' time, when the engineering design phase of ITER is complete. Japan has settled on a site at Naka, and the United States is likely to choose one of several Department of Energy sites previously engaged in defence work, such as Savannah River in Georgia.

Germany has long been considered a leading candidate for Europe's next fusion reactor, following its decision in the early 1970s to support the construction of the Joint European Torus (JET) at Culham in Britain.
Alison Abbott

\section{France in bid to avoid deadlock over LHC decision}

Munich. The French government was said last week to have offered to provide an extra contribution 'in kind' thought to be worth between FFr50 million (US\$8.5 million) and FFr100 million above its annual contribution to the European Laboratory for Particle Physics (CERN) in order to avoid delays to the construction of the planned Large Hadron Collider (LHC).

But its offer is said to have been dependent on a resolution of a conflict between the management of CERN and the governments of Britain and Germany over two issues that were still threatening to create a deadlock when the CERN council meets on Friday (24 June) to decide whether or not to give the go-ahead to the LHC (see Nature 369, 509; 1994).

Britain was reported to be willing to compromise on the two countries' desire to see a change in voting procedures, which would effectively give a single country the right of veto over any inflation-linked rises during the LHC construction phase.

But Germany's research ministry, suffering from tough budget constraints, was said to be still digging in its heels both over this and a proposal that there should be a full review of the project in 1997.

The United States, Japan and the Soviet Union, are reported to be awaiting the outcome of Friday's meeting before deciding whether - and if so, at what level - to participate.

One country, however, has already indicated its willingness to do so. A draft proposal from India, spelling out the nature of potential collaboration and based on discussions with CERN officials held in Bombay in March, has been forwarded to Geneva, and India's Department of Atomic Energy is awaiting CERN's response.

The total value of an Indian contribution to the proposed LHC programme is expected to be roughly $\$ 50$ million. "But we will not be paying any cash", says a spokesman for the DAE, adding that India is proposing to provide manpower and supply hardware such as magnets and detectors for LHC, as well as "undertake any specific task assigned to us".

If the accelerator goes ahead, the monetary value of all these contributions will be assessed by CERN, and half of that value will be treated as payment toward LHC, the spokesman said. The remaining half would be used to meet the expenses of Indian scientists working in Geneva.

DAE says Indian participation in $\mathrm{LHC}$ is necessary not only to enable Indian scientists to take part in such experiments, but also "to establish our known expertise in high technology in the international scene". 